\title{
Effects of Exogenous 6-Benzyladenine on Dwarfing, Shoot Branching, and Yield of Tea Plant (Camellia sinensis)
}

\author{
Liping Zhang \\ Key Laboratory of Tea Quality and Safety Control, Ministry of Agriculture, \\ Tea Research Institute, Chinese Academy of Agricultural Sciences, \\ Hangzhou 310008, China
}

\section{Chen Shen and Jipeng Wei}

Key Laboratory of Tea Quality and Safety Control, Ministry of Agriculture, Tea Research Institute, Chinese Academy of Agricultural Sciences, Hangzhou 310008, China; and Graduate School of Chinese Academy of Agricultural Sciences, Beijing 100081, China

\section{Wenyan Han ${ }^{1}$ \\ Key Laboratory of Tea Quality and Safety Control, Ministry of Agriculture, Tea Research Institute, Chinese Academy of Agricultural Sciences, Hangzhou 310008, China \\ Additional index words. cytokinin, lateral branch, new shoot, photosynthesis, yield}

\begin{abstract}
Benzyladenine (6-BA) is a safe and efficient cytokinin. The adult tea plants of the cv. Longjing 43 were used in this study. The foliar portion of tea bushes were sprayed with different concentrations $\left(50,100,200\right.$, or $\left.400 \mathrm{mg} \cdot \mathrm{L}^{-1}\right)$ of $6-\mathrm{BA}$ after heavy pruning, when three to four leaves grew out in late May. The effects of 6-BA application on the growth of the new shoots and lateral branches were quantified. After 5 months, treatments with $50,100,200$, or $400 \mathrm{mg} \cdot \mathrm{L}^{-1}$ 6-BA suppressed plant height by $11.0 \%$, $18.0 \%, 21.0 \%$, or $22.0 \%$, respectively; $6-\mathrm{BA}$ at 100,200 , or $400 \mathrm{mg} \cdot \mathrm{L}^{-1}$ decreased the number of lateral branches by $20.0 \%, 23.0 \%$, or $18.0 \%$, respectively. Meanwhile, treatments with 50,200 , or $400 \mathrm{mg} \cdot \mathrm{L}^{-1}$ 6-BA increased the length of lateral branches by $38.0 \%, 79.0 \%$, or $81.0 \%$ respectively; $200 \mathrm{mg} \cdot \mathrm{L}^{-1} 6-\mathrm{BA}$ increased the diameter of lateral branches by $8.0 \%$. In addition, after 2 months, 50 or $200 \mathrm{mg} \cdot \mathrm{L}^{-1}$ 6-BA did not significantly affect the growth of functional leaves, 50,100 , or $200 \mathrm{mg} \cdot \mathrm{L}^{-1}$ 6-BA did not significantly affect photosynthetic rate (Pn) as compared with the control. Furthermore, 200 or $400 \mathrm{mg} \cdot \mathrm{L}^{-1}$ 6-BA significantly increased spring tea yield by $28.9 \%$ or $13.3 \%$, respectively as compared with the control. In conclusion, 6-BA at the four concentrations promoted dwarfing and the formation of productive lateral branches and increased the spring yield, and $200 \mathrm{mg} \cdot \mathrm{L}^{-1} 6-\mathrm{BA}$ exerted the best comprehensive effect.
\end{abstract}

Shoot branching, being a major agronomic trait affecting crop yield, is a topic of concern in cultivation (Chen et al., 2016; Muhr et al., 2016). The regulation of shoot branching is an important aspect for crop improvement in agricultural production (Chen et al., 2016; Muhr et al., 2016), and there are fewer studies on branching of woody plants (Chen et al., 2016; Dun et al., 2012; Li et al., 2003). Tea (Camellia sinensis) is an important economic crop with bud leaves in the lateral branches as its product organ (Tounekti et al., 2013; Wu et al., 2015). A sufficient number of leaf buds is necessary

\footnotetext{
Received for publication 19 Jan. 2018. Accepted for publication $26 \mathrm{Feb} .2018$.

This study was funded by the Innovation Project of the Chinese Academy of Agricultural Sciences (CAAS-ASTIP-2015-TRICAAS-08) and also by the Key Project of International Science \& Technology Cooperation, National Key Research and Development Programme of China (2017YFE0107500).
}

${ }^{1}$ Corresponding author. E-mail: hanwy@tricaas.com. to obtain high yield and quality (Yao and $\mathrm{Wu}$, 1990). However, the apical dominance of the tea plant is obvious, and the growth of lateral buds is usually inhibited by apical buds (Yue et al., 2012). In tea production, mature tea plants are regularly pruned to promote the growth of lateral branches, thus ensuring that there are sufficient bud leaves in the population of tea plants (Yue et al., 2012).

Plant hormones play critical roles in regulating shoot branching, and plant growth regulators are commonly applied to promote shoot branching in crop production, thus minimizing the occurrence of pruningcaused diseases and reducing labor cost (Kender and Carpenter, 1972). Cytokinins are plant hormones that regulate cell division and play central roles in shoot branching (Brenner and Schmülling, 2012). Several studies showed that cytokinins synthesized in the stem node play important roles in axillary bud outgrowth (Chen et al., 2016). Axillary buds with high cytokinin concentrations grow faster than those with low concentrations
(Emery et al., 1998). Exogenous cytokinin application promotes lateral bud outgrowth (Dierck et al., 2016; Dun et al., 2012; Liu et al., 2009). For example, foliar spraying of cytokinins in spring could promote tea buds outgrowth (Li, 1990). Apple (Malus pumila) and sweet cherry (Prunus avium) can be treated with cytokinins to produce seedlings with lateral branches of the desired height (Elfving and Visser, 2006). Cytokinin application to axillary buds promotes axillary bud outgrowth (Shimizu-Sato et al., 2009). Isopentenyltransferase (IPT) is a ratelimiting enzyme in cytokinin biosynthesis (Yu et al., 2012). IPT-overexpressing transgenic plants such as kiwifruit (Actinidia deliciosa) and Asakura-sanshoo (Zanthoxylum piperitum) (Zeng and Zhao, 2016) have many lateral branches and short internodes (Honda et al., 2011).

6-Benzyladine is a safe and efficient synthetic cytokinin mainly used in crop production to promote non-meristem differentiation and lateral bud outgrowth (Sprent, 1967). 6-BA application directly promotes lateral bud growth. For example, Liu et al. (2009) reported that exogenous 6-BA application stimulates the outgrowth of wheat tiller buds. Exogenous 6-BA application promotes the outgrowth of lateral buds in jatropha (Jatropha curcas) (Ni et al., 2015) and lupine (Lupinus micranthus) (Emery et al., 1998). Foliar spraying of 6-BA significantly stimulates axillary buds outgrowth in young (Huang et al., 1999; Kender and Carpenter, 1972) and nursery (Elfving and Visser, 2006; Meng et al., 2012) apple trees.

The tea polyphenols (TP) to amino acids (AA) ratio is one of the decisive factors which affects the quality of green tea $(\mathrm{Li}$ et al., 2016). Based on the harvest seasons, Chinese green tea can be divided into three types such as spring tea, summer tea, and autumn tea (Xu et al., 2012). Spring teas, which are harvested before late May, comprise a higher level of AA but a moderate level of TP, resulting in an optimum TP to AA ratio (Li et al., 2016). For the shrub-type adult tea garden in which only spring tea is picked up, it is usually pruned twice every year in tea production, i.e., heavy pruning in summer (in mid to late April) and pruning in autumn (in late July to early August). So far, there are no reports about the studies on promoting shoot branching of tea plant using 6 -BA after heavy pruning in summer. The adult tea plants of Longjing 43 were used in the present study. The promoting effect of exogenous 6-BA on tea plant dwarfing, lateral bud sprouting in advance, lateral branch growth, and spring tea yield was explored.

\section{Materials and Methods}

Plant material, growth conditions, and 6-BA treatment. Adult tea plants of the widely grown cv. Longjing 43 in China, which is a premium clone for green tea, were used in this study. The experiment was conducted in the tea garden of the Tea Research Institute, Chinese Academy of Agricultural Sciences, No. 9 
Meiling South Road, Xihu District, Hangzhou, Zhejiang province, China (lat. $30^{\circ} 140^{\prime} \mathrm{N}$ and long. $120^{\circ} 100^{\prime} \mathrm{E}, 16 \mathrm{~m}$ above sea level).

Different concentrations of 6-BA working solution $\left(50,100,200\right.$, and $400 \mathrm{mg} \cdot \mathrm{L}^{-1}$; J\&K Scientific Ltd., China) were prepared by adding solute in distilled $\mathrm{H}_{2} \mathrm{O}$ followed by adding $1.0 \%$ hydrochloride, and the mixture was stirred until dissolution. Nonionic surfactant was added before spraying. Control (0 $\mathrm{mg} \cdot \mathrm{L}^{-1}$ ) tea bushes were simultaneously sprayed with distilled $\mathrm{H}_{2} \mathrm{O}$ containing the same ratio of hydrochloride and nonionic surfactant. Each treatment comprises three replications, and each replication spans an area of $10 \mathrm{~m}^{2}$ consisting of 20 tea bushes. For the present study, tea plants that were heavily pruned in late April were chosen. When the apical buds and three to four leaves below the bud grew out in late May, the foliar portion of tea bushes was sprayed with different concentrations of 6-BA solution.

Index measurement and methods. The plant height, the number of lateral buds (or branches), and the length of new shoots, internodes, and lateral buds (or branches) were measured 1,2 , and 5 months after 6-BA application. The new shoots refer to the new branches sprouting from the main shoots after heavy pruning in summer. The length of all the internodes on one new shoot was measured and the average length was used as a replication. The diameter of all the lateral branches on one new shoot was measured using a vernier caliper and the average diameter was used as a replication. For each treatment, 15-30 new shoots, lateral buds (or branches), or tea bushes were tested.

At 1 and 2 months after 6-BA application, Pn was measured on the third fully expanded leaves in 12 tea bushes under each treatment by using an open-flow infrared gas analyzer adapted with light and temperature control systems (Li-COR 6400; Lincoln, NE). The measurement was performed within the time period from 8:00 AM to 11:00 AM maintaining the air temperature, relative humidity, $\mathrm{CO}_{2}$ concentration, and photosynthetic photon flux density at $25^{\circ} \mathrm{C}, 80.0 \%, 400 \mu \mathrm{mol} \cdot \mathrm{mol}^{-1}$ and $800 \mu \mathrm{mol} \cdot \mathrm{m}^{-2} \cdot \mathrm{s}^{-1}$, respectively.

The leaf area of the third fully expanded leaves was measured using a portable leaf area meter (LI-3000C; LI-COR, Lincoln, NE), and five to six replications (with one leaf in each shoot as a replication) were measured for each treatment. A square frame with $0.1 \mathrm{~m}^{2}$ area was made using a hard iron wire. The number of leaf buds in the range of the square frame was counted and the density of bud (bud $/ \mathrm{m}^{2}$ ) was calculated. Meanwhile, the 100 buds and leaf buds in the range of the square frame were weighted and the yield $\left(\mathrm{g} / \mathrm{m}^{2}\right)$ was calculated.

Statistical analysis. Data were analyzed using Statistica (SAS Institute, Inc., Cary, NC, http://www.statsoft.com). In each figure and Table 1, the differences of each index among different concentrations of 6-BA application at each time point were analyzed using one-way analysis of variance (ANOVA); if the ANOVA analysis was significant $(P<0.05)$, Duncan's multiple range test was used to detect significant differences between means.

\section{Results}

Effect of 6-BA on the plant height and the number of lateral buds (or branches) of tea plants. After 1 month, the height of tea plants treated with $50,100,200$, or $400 \mathrm{mg} \cdot \mathrm{L}^{-1}$ 6 -BA decreased by $4.7 \%, 11.3 \%, 11.8 \%$, or $16.0 \%$, respectively. After 2 months, it decreased by $6.2 \%, 13.7 \%, 15.4 \%$, or $18.7 \%$, respectively. After 5 months, it decreased by $11.0 \%, 17.8 \%, 20.6 \%$, or $22.2 \%$, respectively (Fig. 1A). At 1, 2, and 5 months after 6-BA application, the height of tea plants sprayed with the four concentrations of 6-BA was significantly lower than that of the control plants, and the degree of inhibition increased with increasing 6-BA concentration.

Treatment with $50,100,200$, or $400 \mathrm{mg} \cdot \mathrm{L}^{-1}$ 6-BA for 1 month increased the number of lateral buds by $97.0 \%, 142.0 \%, 162.0 \%$, or $172.0 \%$, respectively, compared with the control. This result indicates that the degree of increase in the number of lateral buds under 6BA treatment is highly concentration specific. After 2 months, the number of lateral buds increased with increasing 6-BA concentrations, but no significant difference was observed among the four treatments. After 5 months, treatment with 100,200 , or $400 \mathrm{mg} \cdot \mathrm{L}^{-1} 6-\mathrm{BA}$ decreased the number of lateral branches by $20.0 \%, 23.0 \%$, or $18.0 \%$, respectively, and 6 $\mathrm{BA}$ at $50 \mathrm{mg} \cdot \mathrm{L}^{-1}$ did not significantly affect the number of lateral branches as compared with the control (Fig. 1B).

Effect of 6-BA on the growth of new shoots and lateral branches of tea plants. As shown

Table 1. Effects of 6-Benzyladenine (6-BA) on the growth and yield of spring tea. Tea bushes were sprayed with $50,100,200$, or $400 \mathrm{mg} \cdot \mathrm{L}^{-1}$ 6-BA solution. Control $\left(0 \mathrm{mg} \cdot \mathrm{L}^{-1}\right.$ 6-BA) tea bushes were simultaneously sprayed with distilled $\mathrm{H}_{2} \mathrm{O}$. The density of bud, weight of $100 \mathrm{buds}$, and yield were measured in early April of the following spring. Data shown were means $\pm \operatorname{SE}(n=6)$. Letters indicate significant differences in each index among different concentration of 6-BA application $(P<0.05$, Duncan's multiple range test).

\begin{tabular}{cccc}
\hline 6-BA concn $\left(\mathrm{mg} \cdot \mathrm{L}^{-1}\right)$ & Density of bud $\left(\mathrm{bud} / \mathrm{m}^{2}\right)$ & Wt of 100 buds $(\mathrm{g})$ & Yield $\left(\mathrm{g} / \mathrm{m}^{2}\right)$ \\
\hline 0 & $2,380 \pm 240.2 \mathrm{a}$ & $5.80 \pm 0.136 \mathrm{~b}$ & $143.9 \pm 16.86 \mathrm{a}$ \\
50 & $2,523 \pm 164.4 \mathrm{ac}$ & $6.30 \pm 0.46 \mathrm{ab}$ & $166.8 \pm 13.57 \mathrm{ab}$ \\
100 & $2,703 \pm 155.3 \mathrm{bc}$ & $6.78 \pm 0.171 \mathrm{ac}$ & $181.7 \pm 10.26 \mathrm{ab}$ \\
200 & $2,957 \pm 127.1 \mathrm{~b}$ & $7.42 \pm 0.523 \mathrm{c}$ & $185.5 \pm 6.90 \mathrm{~b}$ \\
400 & $2,723 \pm 208.4 \mathrm{bc}$ & $6.53 \pm 0.608 \mathrm{a}$ & $163 \pm 8.94 \mathrm{ab}$ \\
\hline
\end{tabular}
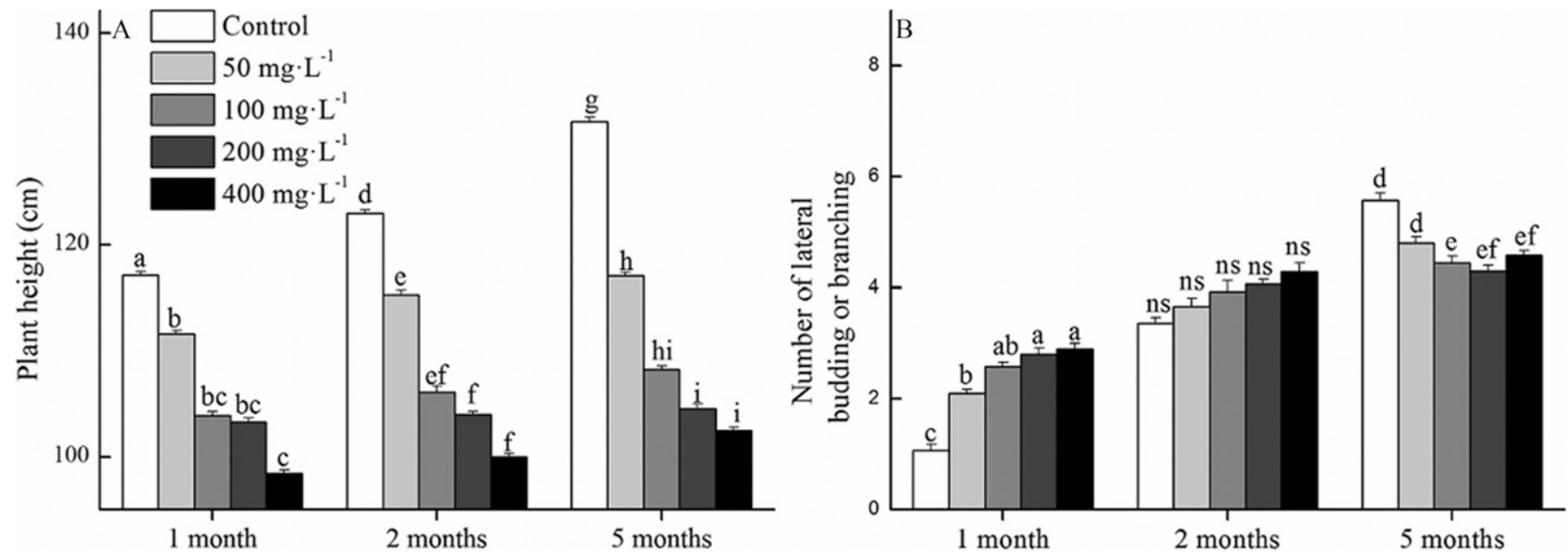

Fig. 1. Effect of different concentrations of 6-Benzyladenine (6-BA) on the height (A) and the number of lateral buds or branches (B) of tea plants. Tea bushes were sprayed with $50,100,200$ or $400 \mathrm{mg} \cdot \mathrm{L}^{-1}$ 6-BA solution. Control $\left(0 \mathrm{mg} \cdot \mathrm{L}^{-1}\right.$ 6-BA) tea bushes were simultaneously sprayed with distilled $\mathrm{H}_{2} \mathrm{O}$. The indexes in each figure were measured at 1,2, and 5 months after 6-BA application. Error bars indicate SE. Letters indicate significant differences in each index among different treatment at each time point $(P<0.05$, Duncan's multiple range test). 
in Fig. 2A, the different concentrations of 6-BA significantly inhibited new shoot growth after 1 and 2 months. Moreover, the degree of inhibition of 100 and $200 \mathrm{mg} \cdot \mathrm{L}^{-1} 6-\mathrm{BA}$ was significantly greater than that of $50 \mathrm{mg} \cdot \mathrm{L}^{-1}$ 6-BA, no significant differences were noted between 100 and $200 \mathrm{mg} \cdot \mathrm{L}^{-1}$ 6-BA, and 400 $\mathrm{mg} \cdot \mathrm{L}^{-1}$ 6-BA had the strongest effect. After 5 months, 50, 100, 200, or $400 \mathrm{mg} \cdot \mathrm{L}^{-1}$ 6-BA application reduced new shoot length by $13.0 \%, 15.0 \%, 25.0 \%$, or $28.0 \%$, respectively, as compared with the control. This result implies that the inhibition degree of 6-BA on new shoot growth increased with increasing 6BA concentration after 5 months. Moreover, $400 \mathrm{mg} \cdot \mathrm{L}^{-1}$ 6-BA inhibited new shoot growth excessively and there were excessive and finer lateral branches after $400 \mathrm{mg} \cdot \mathrm{L}^{-1}$ 6-BA treatment for 5 months.

After 1 month, $400 \mathrm{mg} \cdot \mathrm{L}^{-1}$ 6-BA significantly reduced the internode length of new shoots by $5.1 \%$ as compared with the control, whereas no significant differences were noted among the other four treatments. The internode lengths of the tea plants treated with 100,200 , or $400 \mathrm{mg} \cdot \mathrm{L}^{-1}$ 6-BA were significantly shorter than those of the control plants after 2 months. After 5 months, 50, 200 , or $400 \mathrm{mg} \cdot \mathrm{L}^{-1}$ 6-BA significantly reduced the internode length by $17.0 \%, 20.0 \%$, or $21.0 \%$, respectively (Fig. 2B). After 1 and 2 months, the lateral bud (or branch) lengths of the tea plants treated with 100,200 , or 400 $\mathrm{mg} \cdot \mathrm{L}^{-1}$ 6-BA significantly increased compared with that of the control plants. At 5 months after 6-BA application, the lateral branches of the tea plants treated with 50 , 200 , or $400 \mathrm{mg} \cdot \mathrm{L}^{-1} 6-\mathrm{BA}$ were $38.0 \%, 79.0 \%$, or $81.0 \%$ longer than that of the control plants, respectively (Fig. 2C). At the same period, $200 \mathrm{mg} \cdot \mathrm{L}^{-1}$ 6-BA significantly increased the lateral branch diameter by $7.5 \%$ as compared with the control, whereas no significant differences were noted among the other four treatments (Fig. 2D).

Effect of 6-BA on the growth of tea leaves. The leaf areas of the third fully expanded leaves were measured using a portable leaf area meter. As shown in Fig. 3A, the leaf areas treated with $50,100,200$, or $400 \mathrm{mg} \cdot \mathrm{L}^{-1}$ 6 -BA reduced by $37.0 \%, 40.0 \%, 52.0 \%$, or $54.0 \%$ after 1 month, respectively, compared with those of the control plants. Hence, the inhibition degree of 6-BA strengthened with increasing concentration. After 2 months, 100 or $400 \mathrm{mg} \cdot \mathrm{L}^{-1}$ 6-BA significantly inhibited leaf growth when compared with the control, whereas no significant differences in leaf areas were noted among the other three treatments.

Effect of 6-BA on Pn in tea plants. To understand the photosynthetic response of tea plants to 6-BA, the Pn of the third fully expanded leaves was determined after 6-BA treatment. As shown in Fig. 3B, 50, 100, 200, or $400 \mathrm{mg} \cdot \mathrm{L}^{-1} 6$-BA application for a month suppressed Pn in tea plants by $13.0 \%, 16.0 \%$, $16.0 \%$, or $16.0 \%$, respectively, as compared with the control. However, except for 400 $\mathrm{mg} \cdot \mathrm{L}^{-1} 6-\mathrm{BA}$, the other three concentrations of 6-BA treatment did not significantly affect $\mathrm{Pn}$ as compared with the control after 2 months.

The aforementioned results suggest that the changes induced by 6-BA application on the leaf areas and $\mathrm{Pn}$ of the third fully expanded leaves show similar trends. Thus, the decreased Pn after 6-BA treatment may

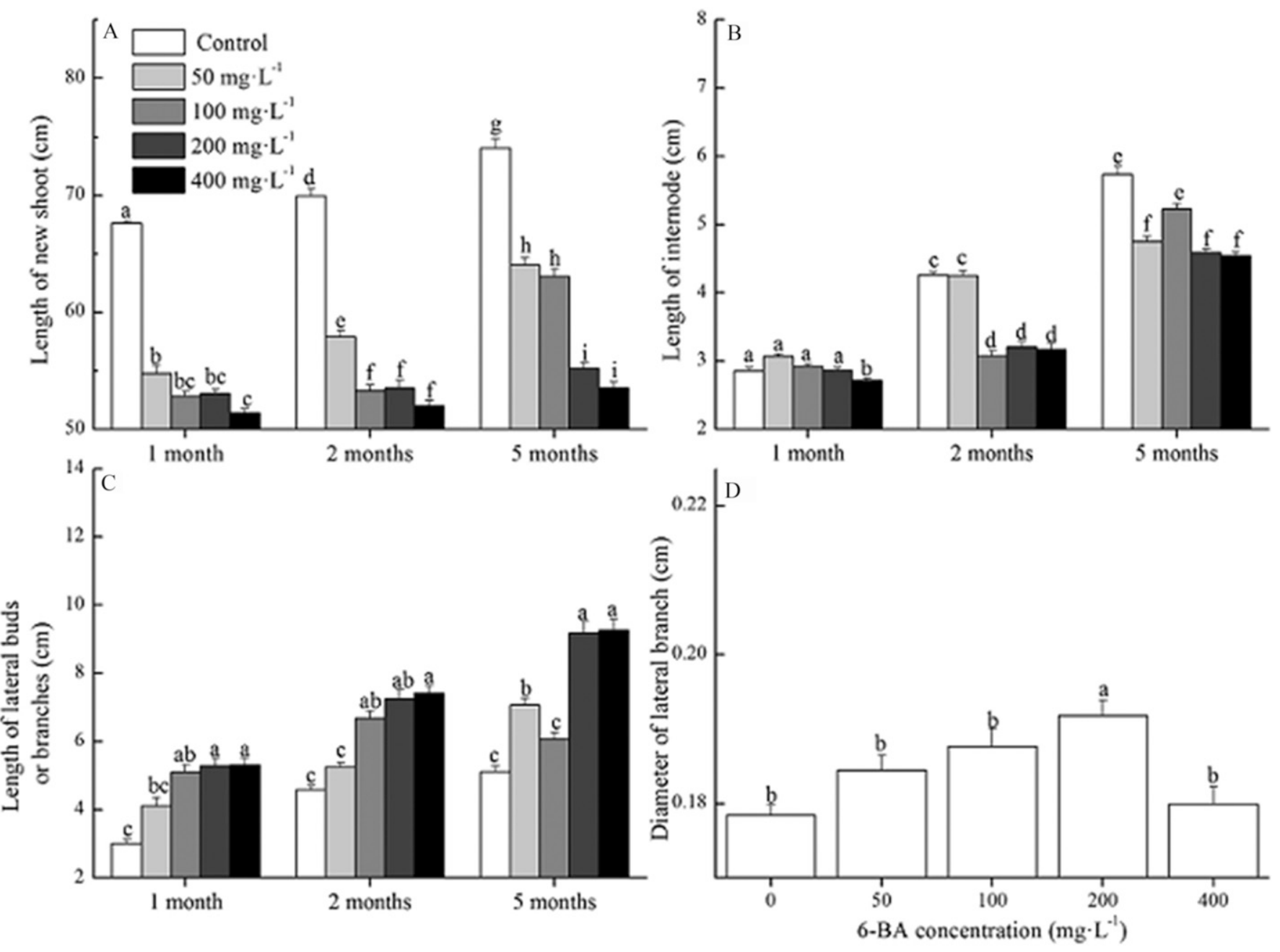

Fig. 2. Effect of different concentrations of 6-Benzyladenine (6-BA) on the lengths of new shoots (A), internode (B), and lateral buds or branches (C), and on the diameter of lateral branches (D) of tea plants. Tea bushes were sprayed with 50, 100, 200, or $400 \mathrm{mg} \cdot \mathrm{L}^{-1}$ 6-BA solution. Control $\left(0 \mathrm{mg} \cdot \mathrm{L}^{-1} 6-\mathrm{BA}\right)$ tea bushes were simultaneously sprayed with distilled $\mathrm{H}_{2} \mathrm{O}$. At 1,2, and 5 months after 6-BA application, the indexes in panels A-C were measured, respectively; at 5 months after 6-BA application, the diameter of lateral branches in panel $\mathbf{D}$ was measured. Error bars indicate sE. Letters indicate significant differences in each index among different treatment at each time point $(P<0.05$, Duncan's multiple range test). 

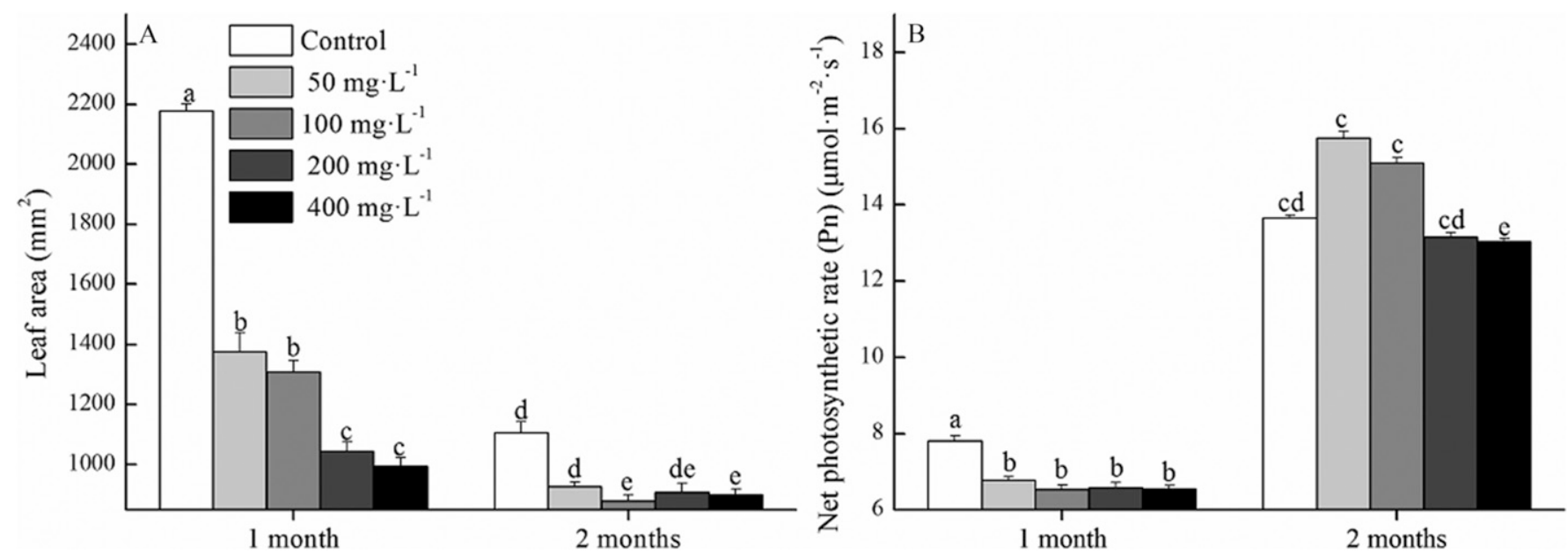

Fig. 3. Effect of different concentrations of 6-Benzyladenine (6-BA) on the leaf area (A) and photosynthetic rate (Pn, B) of tea functional leaves. Tea bushes were sprayed with $50,100,200$, or $400 \mathrm{mg} \cdot \mathrm{L}^{-1}$ 6-BA solution. Control $\left(0 \mathrm{mg} \cdot \mathrm{L}^{-1}\right.$ 6-BA) tea bushes were simultaneously sprayed with distilled $\mathrm{H}_{2} \mathrm{O}$. The leaf area (A) and Pn (B) of tea functional leaves were measured 1 and 2 months after 6-BA application. Error bars indicate sE. Letters indicate significant differences in each index among different treatment at each time point $(P<0.05$, Duncan's multiple range test).

be partly because of the inhibited leaf growth after 1 month of 6-BA application. Considering that the unpruned tea plants have stopped growing and no new shoots appeared in November, we did not measure the leaf area and Pn after 5 months of 6-BA application. Thus, except for the inhibition of 400 $\mathrm{mg} \cdot \mathrm{L}^{-1}$ 6-BA on Pn, the other three concentrations of 6-BA did not significantly affect Pn of functional leaves after 2 months as compared with the control.

Effect of 6-BA on spring tea yield. To assess the effect of 6-BA treatment on growth and biomass production in tea plants, we measured the leaf mass, density of tea bud, weight of 100 buds, and spring tea yield in early April of the following spring. The results showed that there were no significant differences in the leaf mass among different treatments (data not shown). The density of tea buds increased with 100,200 or 400 $\mathrm{mg} \cdot \mathrm{L}^{-1}$ 6-BA, among which $200 \mathrm{mg} \cdot \mathrm{L}^{-1}$ 6-BA had the strongest effect. Likewise, weight of 100 buds showed an increased value under 100,200 or $400 \mathrm{mg} \cdot \mathrm{L}^{-1} 6$-BA treatment, where $200 \mathrm{mg} \cdot \mathrm{L}^{-1}$ 6-BA had the greatest effect. Similar to the trends in density of bud, 200 or $400 \mathrm{mg} \cdot \mathrm{L}^{-1}$ 6-BA treatment significantly increased the yield by $28.9 \%$ or $13.3 \%$, respectively, as compared with the control (Table 1).

\section{Discussion}

Shoot branching is an important agronomic trait that determines the plant morphology aboveground, thereby affecting crop yield and quality (Chen et al., 2016; Muhr et al., 2016). The occurrence, development, and regulatory factors of shoot branching have been widely studied in the recent decades, however, these studies mainly focused on herbaceous plants, such as rice (Orvza sativa), maize (Zea mays), Arabidopsis (Arabidopsis thaliana), pea (Pisum sativum), petunia (Petunia axilaris), and tomato (Solanum lycopersicum) (Dun et al., 2012; Li et al., 2003), and rarely on woody plants.

Plant growth regulators are usually used to promote shoot branching in fruit production (Kender and Carpenter, 1972). For example, exogenous application of morphactin can break the lateral bud dormancy of citrus seedlings, promote dwarfing and produce bushy young apple trees (Roversi, 1971). Gibberellins stimulate axillary bud activity and inhibit the extension growth of the apical meristems of tea plant (Kagira, 1975; Liang et al., 1997; Maudu et al., 2011). Cytokinins are a class of plant hormones that play key roles in regulating plant cell division and development (Kakimoto, 2003; Sakakibara et al., 2006; Werner et al., 2001, 2003). They are reportedly involved in the outgrowth and dormancy of lateral buds (Hitoshi et al., 2006; Sachs and Thimann, 1967) and exogenous cytokinin application could promote the occurrence and growth of axillary buds (Anger et al., 1973; Chatfield et al., 2000; Liu et al., 2009). 6-Benzyladenine is a cytokininlike substance that is widely applied in agriculture production at present. Exogenous 6-BA application could promote the growth of lateral buds and lateral branches (Elfving and Visser, 2006; Ono et al., 2005).

The apical dominance of tea plant is obvious and its growth must be controlled artificially to promote the formation of new shoots. In the present study, different concentrations of 6-BA were sprayed to heavily pruned, mature tea plants when three to four leaves grew out in late May. The results showed that four concentrations of 6-BA significantly inhibited new shoot growth (i.e., promoted dwarfing) and increased the number of lateral buds after 1 month but decreased the number of lateral branches after 5 months. 6-Benzyladenine treatment also increased the length of lateral buds (or branches) and the diameter of lateral branches after 5 months. In the later stage, 6-BA treatment may promote the transferring of more nutrition into sprouting lateral buds as compared with the control, thus promoting the growth of lateral branches and inhibiting late lateral budbreaking. So it is concluded that 6-BA treatment can promote early lateral bud release and productive lateral branch formation, and inhibit invalid lateral branch formation. Among the four concentrations, $200 \mathrm{mg} \cdot \mathrm{L}^{-1}$ 6-BA exhibited the best comprehensive effect. Consistent with this study, previous studies reported that 6-BA application promotes axillary bud outgrowth and lateral branch growth in different plants. For example, 6-BA application to axillary buds inhibits shoot growth and induces branching of peas (Sprent, 1967). 6-Benzyladenine treatment stimulates the breaking of rice tiller buds (Liu et al., 2009).

In addition, the present study showed that 6-BA application did not significantly affect the growth and $\mathrm{Pn}$ of functional leaves. Furthermore, different concentrations of 6-BA treatment significantly increased spring tea yield and among which $200 \mathrm{mg} \cdot \mathrm{L}^{-1}$ 6-BA exerted the best comprehensive effect. Therefore, it can be concluded that exogenous 6-BA application may enhance the photosynthetic performance of colony leaves by increasing the number of productive lateral branches and functional leaves. Thus, this treatment helps increase spring tea yield of tea plants.

In summary, the results of this study showed that foliage spraying of a suitable concentration of 6-BA after heavy summer pruning could inhibit overgrowth of the tea plant, promote formation of productive lateral branches, and increase spring tea yield of Longjing 43 adult tea plants. It is concluded that for shrub-type adult tea garden in which only spring tea was picked up, tea plants usually need pruning twice every year, thus 6-BA application could avoid autumn pruning and promote the continuous growth of tea plants, thereby saving assimilation product, reducing labor cost, and avoiding pruninginduced diseases. 
It is suggested to spray the adult tea plants of the cv. Longjing 43 with $200 \mathrm{mg} \cdot \mathrm{L}^{-1} 6$-BA after heavy pruning in summer, when the axillary buds grow out three to four leaves, which could reduce labor cost and improve labor efficiency. For shrub-type adult tea garden in which only spring tea was picked up, the results of this study can serve as a theoretical basis for providing a novel strategy for tea cultivation management, thus avoiding pruning in autumn once a year. The developed technique can also be applied to the different tea varieties with similar branching characteristics when grown in regions with similar site conditions. However, the promotion effects of 6-BA on dwarfing and lateral shoot formation in other tea plant varieties grown under different site conditions need further study.

\section{Literature Cited}

Anger, R.H.M., P.C. Prasad, and H.M. Laude. 1973. Effects of kinetin on tiller bud elongation in wheat (Triticum aestivum L.). Ann. Bot. 37:565-571.

Brenner, W.G. and T. Schmülling. 2012. Transcript profiling of cytokinin action in Arabidopsis roots and shoots discovers largely similar but also organ-specific responses. BMC Plant Biol. $12: 112$.

Chatfield, S.P., P. Stirnberg, B.G. Forde, and O. Leyser. 2000. The hormonal regulation of axillary bud growth in Arabidopsis. Plant J. 24:159-169.

Chen, X.J., X.J. Xia, X. Guo, Y.H. Zhou, K. Shi, J. Zhou, and J.Q. Yu. 2016. Apoplastic $\mathrm{H}_{2} \mathrm{O}_{2}$ plays a critical role in axillary bud outgrowth by altering auxin and cytokinin homeostasis in tomato plants. New Phytol. 211:1266-1278.

Dierck, R., E.D. Keyser, J.D. Riek, E. Dhooghe, J.V. Huylenbroeck, E. Prinsen, and D.V.D. Straeten. 2016. Change in auxin and cytokinin levels coincides with altered expression of branching genes during axillary bud outgrowth in Chrysanthemum. PLoS One 11(8): $\mathrm{e} 0161732$.

Dun, E.A., A.S. Germain, C. Rameau, and C.A. Beveridge. 2012. Antagonistic action of strigolactone and cytokinin in bud outgrowth control. Plant Physiol. 158:487-498.

Elfving, D.C. and D.B. Visser. 2006. Timing cyclanilide and cytokinin applications in the nursery to obtain desired lateral branch height in apple and sweet cherry trees. HortScience 41:1238-1242.

Emery, R.J.N., N.E. Longnecker, and C.A. Atkins. 1998. Branch development in Lupinus angustifolius L. II. Relationship with endogenous ABA, IAA and cytokinins in axillary and main stem buds. J. Expt. Bot. 49(320):555-562.

Hitoshi, S., T. Kentaro, and H. Naoya. 2006. Interactions between nitrogen and cytokinin in the regulation of metabolism and development. Trends Plant Sci. 11:440-448.

Honda, C., S. Kusaba, T. Nishijima, and T. Moriguchi. 2011. Transformation of kiwifruit using the ipt gene alters tree architecture. J. Plant Biotech. 107:45-53.

Huang, W.D., Z.H. Han, S. Liu, X.F. Xu, and B. Li. 1999. Effects of point-daub with 6-BA ointment on bud breaking, shoot growth, and the shaping of young apple trees (in Chinese). Rev. China Agr. Sci. Technol. 2:72-75.

Kagira, C.N. 1975. Stimulation of branching in young tea plants. Acta Hort. 49:137-146.

Kakimoto, T. 2003. Perception and signal transduction of cytokinins. Annu. Rev. Plant Biol. 54:605-627.

Kender, W.J. and S. Carpenter. 1972. Stimulation of lateral bud growth of apple trees by 6-benzylamino purine. J. Amer. Soc. Hort. Sci. 97:377-380.

Li, X., G.J. Ahammed, Z.X. Li, L. Zhang, J.P. Wei, C. Shen, P. Yan, L.P. Zhang, and W.Y. Han. 2016. Brassinosteroids improve quality of summer tea (Camellia sinensis L.) by balancing biosynthesis of polyphenols and amino acids. Front. Plant Sci. 7:1304.

Li, X.G. 1990. The effects of cytokinin spraying on the tea plants (in Chinese). Chinese tea 2:33.

Li, X.Y., Q. Qian, Z.M. Fu, Y.H. Wang, G.S Xiong, D.L. Zeng, X.Q. Wang, X.F. Liu, S. Teng, F. Hiroshi, M. Yuan, D. Luo, B. Han, and J.Y. Li. 2003. Control of tillering in rice. Nature 422:618-621.

Liang, Y., J. Lu, and S. Shang. 1997. Effect of gibberellins on chemical composition and quality of tea (Camellia sinensis L). J. Sci. Food Agr. 72:411-414.

Liu, Y., Q.S. Wang, Y.F. Ding, Z.H. Liu, G.H. Li, and S.H. Wang. 2009. Effect of nitrogen and 6-BA on development of tillering bud and its physiological mechanism (in Chinese). Acta Agron. Sinica 35(10):1893-1899.

Maudu, M.E., F.N. Mudau, and I.K. Mariga. 2011. The effect of gibberellins on sprouting of cuttings and quality of bush tea (Athrixia phylicoides DC). Afr. J. Biotechnol. 10(44):8741-8745.

McSteen, P. and O. Leyser. 2005. Shoot branching. Annu. Rev. Plant Biol. 56:353-374.

Meng, Y., S. Ma, J. Shao, J. Sun, B. Ma, and H. Wang. 2012. Effects of spraying 6-BA on axillary bud growth and the dynamic changes of endogenous hormones in 'Tianhong 2' Fuji nursery apple trees (in Chinese). Acta Hort. Sinica 39(5):837-844.

Muhr, M., N. Prüfer, M. Paulat, and T. Teichmann. 2016. Knockdown of strigolactone biosynthesis genes in Populus affects BRANCHED1 expression and shoot architecture. New Phytol. 212:613-626.

Ni, J., C. Gao, M.S. Chen, B.Z. Pa, K. Ye, and Z.F. $\mathrm{Xu}$. 2015. Gibberellin promotes shoot branching in the perennial woody plant Jatropha curcas. Plant Cell Physiol. 56(8):1655-1666.

Ono, T., H. Tamai, T. Maejima, A. Usuda, H. Koike, and H. Ohara. 2005. Effects of repeated benzyladenine spraying on branch development of apple nursery trees on M.9 rootstocks. Hort. Res. 4(2):165-170.

Roversi, A. 1971. The branching property of morphactin on Prunus avium seedlings. Experientia 27(10):1233-1234.

Sachs, T. and K.V. Thimann. 1967. The role of auxins and cytokinins in the release of buds from dominance. Amer. J. Bot. 54:136-144.

Sakakibara, H., K. Takei, and N. Hirose. 2006. Interactions between nitrogen and cytokinin in the regulation of metabolism and development. Trends Plant Sci. 11:440-448.

Shimizu-Sato, S., M. Tanaka, and H. Mori. 2009. Auxin-cytokinin interactions in the control of shoot branching. Plant Mol. Biol. 69:429-435.

Sprent, J.I. 1967. The effects of benzyladenine on the growth and development of peas. Planta 78(1):17-24.

Tounekti, T., E. Joubert, I. Hernández, and S. Munné-Bosch. 2013. Improving the polyphenol content of tea. Crit. Rev. Plant Sci. 32:192215.

Werner, T., V. Motyka, V. Laucou, R. Smets, H.V. Onckelen, and T. Schmülling. 2003. Cytokinindeficient transgenic Arabidopsis plants show multiple developmental alterations indicating opposite functions of cytokinins in the regulation of shoot and root meristem activity. Plant Cell 15:2532-2550.

Werner, T., V. Motyka, M. Strnad, and T. Schmulling. 2001. Regulation of plant growth by cytokinin. Proc. Natl. Acad. Sci. U.S.A. 98:1048710492.

Wu, Z.J., X.H. Li, Z.W. Liu, H. Li, Y.X. Wang, and J. Zhuang. 2015. Transcriptome-based discovery of AP2/ERF transcription factors related to temperature stress in tea plant (Camellia sinensis). Funct. Integr. Genomics 15:741-752.

Xu, W., Q. Song, D. Li, and X. Wan. 2012. Discrimination of the production season of Chinese green tea by chemical analysis in combination with supervised pattern recognition. J. Agr. Food Chem. 60:7064-7070.

Yao, G. and X. Wu. 1990. Formation and regulation of the "optimum type" of tea plant structure (in Chinese). Scientia Agr. Sinica 23(6):62-68.

Yu, J., L.L. Dong, L. Xi, R.Y. Zhao, N. Ma, and L.J. Zhao. 2012. Isolation and characterization of cytokinin synthase gene DgIPT3 in Chrysanthemum 'Jinba' (in Chinese). Acta Hort. Sinica 39(4):721-728.

Yue, C., J. Zeng, Z. Zhang, X. Wang, and H. Cao. 2012. Research progress in the phytohormone of tea plant (Camellia sinensis) (in Chinese). J. Tea Sci. 32(5):382-392.

Zeng, X.F. and D.G. Zhao. 2016. Expression of IPT in Asakura-sanshoo (Zanthoxylum piperitum (L.) DC. f. inerme Makino) alters tree architecture, delays leaf senescence, and changes leaf essential oil composition. Plant Mol. Biol. Rpt. 34:649-658. 